\title{
Vavraia culicis (Weiser, 1947) Weiser, 1977 revisited: cytological characterisation of a Vavraia culicis-like microsporidium isolated from mosquitoes in Florida and the establishment of Vavraia culicis floridensis subsp. $\mathbf{n}$.
}

\author{
Jiří Vávra ${ }^{1,2}$ and James J. Becnel ${ }^{3}$ \\ ${ }^{1}$ Institute of Parasitology, Biology Centre, Academy of Sciences of the Czech Republic, Branišovská 31, 37005 České \\ Budějovice, Czech Republic; \\ ${ }^{2}$ Faculty of Science, University of South Bohemia, Branišovská 31, 37005 České Budějovice, Czech Republic; \\ ${ }^{3}$ USDA/ARS Center for Medical, Agricultural and Veterinary Entomology, 1600 SW 23rd Drive, Gainesville, Florida 32608, \\ USA
}

Key words: Microsporidia, mosquitoes, Vavraia, ultrastructure, light microscopic cytology

\begin{abstract}
A brief nomenclatural history of Vavraia culicis (Weiser, 1947), the type species for the genus Vavraia Weiser, 1977, is presented together with a detailed description of the cytological and ultrastructural characteristics of a Vavraia culicis-like microsporidian species isolated from Aedes albopictus (Scuse) in Florida. This "Florida isolate", is the only known isolate of a species of the genus Vavraia from mosquitoes propagated in laboratory culture. Although the Florida isolate has been used under the name Vavraia culicis in several molecular phylogeny and host-parasite studies, it has not been structurally characterized and its relationship to the type species Vavraia culicis has never been examined. Structural data strongly support placement of the Florida isolate within the genus Vavraia and indicate its close relationship to both the type species of the genus and to other Vavraia-like mosquito microsporidia to which the name $V$. culicis has been applied. However, the identity of the Florida isolate with $V$. culicis (Weiser, 1947) Weiser, 1977 cannot be presently confirmed. Morphometric examination of spores of several Vavraia-like microsporidia isolates from mosquitoes, including the type material of Vavraia culicis, indicates that Vavraia culicis-like microsporidia probably represent not a single species, but a group of closely related organisms. Subspecies status is proposed for the Florida isolate.
\end{abstract}

Vavraia culicis (Weiser, 1947) Weiser, 1977 is the type species of the genus Vavraia Weiser, 1977. The parasite was originally described under the name Plistophora kudoi from a single larva of Culex pipiens (Diptera: Culicidae). The infected larva was collected in a small pond in the town of Chotěbor $\left(49^{\circ} 43^{\prime} 0\right.$ ' $N$, $\left.15^{\circ} 40^{\prime} 0^{\prime \prime} \mathrm{E}\right)$ in the territory of what is now the Czech Republic. The parasite was found in the year 1943 but due to the war situation in Europe, its description was delayed (Weiser 1946). The parasite was later renamed Plistophora culicis as P. kudoi had originally been described as a parasite of a cockroach (Weiser 1947). Canning (1957) published the first detailed light microscope description of what was believed to be $P$. culicis, based on material from Anopheles gambiae adults in a laboratory colony. In 1972, Weiser and Coluzzi described transmission experiments and spore size variability of Plistophora culicis, using a parasite discovered in Culiseta longiareolata in Italy. The parasite, described as Plistophora culisetae Weiser et Coluzzi, 1964, was later proved to be infectious for Culex pipiens and was treated as junior synonym of Plistophora culicis (Weiser and Coluzzi 1972). Under the name Plistophora culicis (Plistophora being later changed to its correct spelling Pleistophora by Clark and Fukuda in
1971) the taxon persisted until 1977 when Weiser created the genus Vavraia and the former P. culicis became its type species (Weiser 1977). The diagnosis of the genus Vavraia has been revised three times based on added ultrastructural characteristics. In 1982, Canning and Hazard redefined the genus, using a $V$. culicis isolate derived from the mosquito Culiseta longiareolata found in Italy and experimentally introduced into three different Anopheles species. Another redefinition was that of Larsson (1986), which, however, was based on a Vavraia holocentropi found in a caddisfly. The last redefinition of the genus was published in 1991, based on infections with an isolate of what was believed to be $V$. culicis found in Anopheles gambiae in Africa (Diarra and Toguebaye 1991). Microsporidia believed to be Vavraia culicis have been reported from mosquito hosts including at least five genera and more than 13 species collected in nature in a broad geographic area including Europe, Africa and North America (Weiser 1946, Weiser and Coluzzi 1964, 1972, Reynolds 1966, 1971, Clark and Fukuda 1971, Chapman 1974, Hazard and Chapman 1977, Fukuda et al. 1997, Diarra and Toguebaye 1991). The organism was also found as a contaminant in laboratory mosquito colonies (Canning 1957, Lobo et al. 2006) (Table 1). The low host-specificity 
and the ability to infect non-mosquito hosts (Weiser 1978, Kelly et al. 1981, Becnel et al. 2005) made microsporidia designated as Vavraia culicis a laboratory tool (Reynolds 1970, Agnew et al. 1999, Cheney at al. 2000, 2001, Bedhomme et al. 2005, Biron et al. 2005, Rivero et al. 2007). It also opened the way to consider $V$. culicis-like microsporidia as mosquito control agents (Reynolds 1972, Kelly et al. 1981, Andreadis 2007). Another interest of Vavraia culicis-like microsporidia from mosquitoes is in the fact that the Florida isolate mentioned below is highly related in phylogeny trees to mammalian opportunistic microsporidia of the genus Trachipleistophora (Cheney et al. 2000, Vávra et al. 2006). Also the structural characters of both genera are very similar (Vávra et al. 2006) and the human pathogen Trachipleistophora hominis is transmissible to mosquitoes (Weidner et al. 1999). It is therefore surprising that no in-depth study has been made in order to critically compare the individual isolates of $V$. culicis-like microsporidia with the type material, to determine whether they represent a single species or a complex of distinct species.

The most recent isolation of a species of Vavraia from mosquitoes (designated as $V$. culicis) has been reported from four mosquito species of two genera (Aedes aegypti, Ae. albopictus, Ae. triseriatus, Orthopodomyia signifera) from Florida where it was concluded that the fine structure was the same in the different hosts, despite the fact that fresh spores were somewhat smaller in Orthopodomyia signifera (Fukuda et al. 1997) (Table 1). The Aedes albopictus parasite found by Fukuda et al. has been propagated in the laboratory both in mosquito and lepidopteran hosts (Becnel et al. 2005). This Florida (FL) isolate represents the only culture of a species of Vavraia isolated from mosquitoes that is maintained and grown under standard conditions. As it is available to other scientists, it has been used under the name Vavraia culicis in molecular phylogeny (Cheney et al. 2000, 2001, Vávra et al. 2006), host-parasite relationship studies (Agnew et al. 1999, Becnel et al. 2005, Bedhomme et al. 2005, Biron et al. 2005) and as comparative material in microsporidia identification (Lobo et al. 2006). The present paper describes the structural characters of the FL isolate and discusses its taxonomic status.

\section{MATERIALS AND METHODS}

Origin of the Florida isolate. A species of Vavraia, believed to represent $V$. culicis was recovered from larvae of Aedes albopictus, Ae. aegypti, Ae. triseriatus and Orthopodomyia signifera collected in Alachua County, Florida, USA, during a survey for pathogens between 1991 and $1994(\mathrm{Fu}-$ kuda et al. 1997). Ae. albopictus was the most common host for this species and the source for the currently maintained FL isolate. Spores from field-collected larvae of Ae. albopictus were used to infect larvae from a laboratory colony of $A e$. albopictus and propagated according to the protocols described below.
Propagation of the Florida isolate. Large numbers of Vavraia spores can be produced in the lepidopteran host Helicoverpa zea. In order to avoid possible selection for an isolate that loses infectivity for mosquitoes, propagation of Vavraia is alternated between $\mathrm{H}$. zea and Anopheles quadrimaculatus as follows. Five-day-old larvae of $H$. zea (approximately 3rd instars) are placed individually into small $(20 \mathrm{ml})$ plastic cups and starved for 24 hours. Individual larvae are provided a small drop (ca. $10 \mu \mathrm{l}$ ) of a spore suspension to yield a final concentration of between $2 \times 10^{2}-2 \times 10^{3}$ spores per larva and held for 24 hours or until the inoculum has been ingested. The larvae are returned to standard diet and reared individually until adult emergence (approximately 30 days). Adults are homogenized in deionized water and filtered through a 140 mesh nylon screen to remove large particulate matter. Spores are purified on a continuous Ludox gradient as described by Undeen and Vávra (1997) and stored at $4^{\circ} \mathrm{C}$. For production in A. quadrimaculatus, approximately 2,000 24-hour-old larvae are exposed to spores of Vavraia (produced in H. zea) in 100 $\mathrm{ml}$ of deionized water to a final concentration of $1 \times 10^{4}-1 \times 10^{5}$ spores $/ \mathrm{ml}$. A small amount of larval food is added and the larvae held for $24 \mathrm{hr}$ and then transferred to a tray with 3 litres of deionized water and fed standard diet. The mosquitoes are reared to the adult stage, homogenized in deionized water and filtered through a 140 mesh nylon screen to remove large particulate matter and the spores are purified and stored as described above.

Structural methods. The data for the present study were obtained from the FL isolate of Vavraia grown in the cotton leafworm Spodoptera littoralis (Boisduval) larvae. Second- or third-instar larvae were infected with spores of the FL isolate mixed with laboratory diet ("wheat-germ-agar ManducaHeliothis premix"- Stonefly Industries, Inc., Texas) and were dissected at different intervals starting from day 7 post infection (p.i.). The data obtained were compared with those obtained on Vavraia grown in Anopheles quadrimaculatus and Helicoverpa zea as mentioned above or with data from Vavraia infecting wild Orthopodomyia signifera larvae (Becnel, unpubl.).

Light microscopy. Published methods of spore immobilization, photography and staining by Giemsa (or Giemsa after acid hydrolysis) were used (Vávra and Maddox 1976). Fresh, agar-immobilized and fixed, Giemsa-stained spores were measured on computer screen using the Olympus M.I.S.Quick PHOTO MICRO programme.

Comparative materials. Morphometric characters for the Florida isolate were compared with those of the following isolates of microsporidia considered by authors to represent $V$. culicis and the Giemsa-stained slides of which were available: type slides of Vavraia culicis from the 1943 original collection of the parasite (Weiser 1946) (isolate CP), slides labeled Vavraia culicis, Culex pipiens, collected in Monticelli, Italy by Weiser and Coluzzi and described in their publications of 1964, 1972 (isolate IT1), slides labeled Plistophora culicis, Anopheles gambiae dealt with in the publication by Canning 1957 (isolate AG1) (Table 1). The respective slides were kindly provided by J. Weiser (isolates CP and IT1) and E.U. Canning (isolate AG1). Spores on slides used for comparison were photographed at exactly the same magnification and were measured as mentioned above. One-Way ANOVA followed by Post Hoc Scheffe Test was used to test for differences in spore size among individual isolates. 
Table 1. Vavraia culicis-like microsporidia from mosquitoes (data on structure and molecular characters).

\begin{tabular}{|c|c|c|c|c|}
\hline Author & Host & $\begin{array}{l}\text { Country } \\
\text { Habitat type }\end{array}$ & $\begin{array}{l}\text { Spore size }(\mu \mathrm{m}) \\
\mathrm{F}-\text { fresh } \\
\mathrm{G}-\text { Giemsa-stained }\end{array}$ & $\begin{array}{l}\text { Remarks and Code of the } \\
\text { isolate, this paper }\end{array}$ \\
\hline Weiser 1946 & Culex pipiens & $\begin{array}{l}\text { Czech Republic, } \\
\text { pond }\end{array}$ & $\begin{array}{l}4.0 \times 2.5(\mathrm{~F}) \\
3.7 \times 2.34(\mathrm{G})(* 1)\end{array}$ & $\begin{array}{l}\mathrm{CP} \text {, the type isolate - Vavraia } \\
\text { culicis culicis }\end{array}$ \\
\hline Canning 1957 & Anopheles gambiae & $\begin{array}{l}\text { England, } \\
\text { laboratory colony }\end{array}$ & $\begin{array}{l}5.1 \times 3.7(\mathrm{~F}) \\
5.9 \times 3.7(\mathrm{G})(* 2) \\
3.7 \times 2.2(\mathrm{~F}) \\
4.0 \times 2.6(\mathrm{G})(* 3) \\
\mathbf{4 . 8} \times \mathbf{3 . 0}(* 1)(\mathrm{G})\end{array}$ & AG1 \\
\hline $\begin{array}{l}\text { Weiser and Coluzzi 1964, } \\
1972\end{array}$ & $\begin{array}{l}\text { Culex spp. } \\
\text { Anopheles spp. } \\
\text { Culiseta longiareolata }\end{array}$ & $\begin{array}{l}\text { Italy, } \\
\text { small outdoor basin }\end{array}$ & $\begin{array}{l}3.0-4.5 \times 2.0-2.7,(\mathrm{G}) \\
3.7 \times 2.5(\mathrm{G})(* 1)(* 4) \\
3.6-4.8 \times 1.8-2.4(\mathrm{G})(* 5)\end{array}$ & $\begin{array}{l}(* 4)-\text { IT1 } \\
(* 5)-\text { IT2 }{ }^{\#)} \\
\text { IT1 and IT2 believed con- } \\
\text { specific by W. and C. } 1972\end{array}$ \\
\hline Canning and Hazard 1982 & Anopheles spp. & $\begin{array}{l}\text { experimental infection } \\
\text { by spores from } \\
\text { C. longiareolata }\end{array}$ & & $\begin{array}{l}\text { Ultrastructural data, } \\
\text { using IT2 material }\end{array}$ \\
\hline Fukuda et al. 1997 & $\begin{array}{l}\text { Aedes spp. } \\
\text { Orthopodomyia } \\
\quad \text { signifera } \\
\end{array}$ & $\begin{array}{l}\text { Florida, USA, } \\
\text { artificial containers }\end{array}$ & $\begin{array}{l}5.4 \times 3.2(\mathrm{~F})(* 6) \\
4.9 \times 3.1(\mathrm{~F})(* 7)\end{array}$ & $\begin{array}{l}\mathrm{FL}-\text { isolate from } \\
\text { Aedes albopictus }(* 6)\end{array}$ \\
\hline $\begin{array}{l}\text { Diarra and Toguebaye } \\
1991\end{array}$ & Anopheles gambiae & $\begin{array}{l}\text { Africa, Senegal, } \\
\text { West Africa, pools }\end{array}$ & & AG2 \\
\hline Cheney et al. 2000 & & FL isolate spores & & Molecular data \\
\hline Cheney et al. 2001 & & FL isolate spores & & Molecular data \\
\hline Lobo et al. 2006 & Anopheles stephensi & $\begin{array}{l}\text { Portugal, } \\
\text { laboratory colony }\end{array}$ & $4.5 \times 2.57(\mathrm{~F})$ & AS \\
\hline This paper & $\begin{array}{l}\text { Anopheles } \\
\quad \text { quadrimaculatus } \\
\end{array}$ & $\begin{array}{l}\text { experimental infection } \\
\text { using FL isolate spores }\end{array}$ & $4.9 \times 2.7(\mathrm{~F})(* 1)$ & $\begin{array}{l}\text { FL isolate - Vavraia culicis } \\
\text { floridensis }\end{array}$ \\
\hline This paper & Helicoverpa zea & $\begin{array}{l}\text { experimental infection } \\
\text { using FL isolate spores }\end{array}$ & $4.7 \times 2.7(\mathrm{~F})(* 1)$ & $\begin{array}{l}\text { FL isolate - Vavraia culicis } \\
\text { floridensis }\end{array}$ \\
\hline This paper & Spodoptera littoralis & $\begin{array}{l}\text { experimental infection } \\
\text { using FL isolate spores }\end{array}$ & $\begin{array}{l}4.7 \times 2.7(\mathrm{~F})(* 1) \\
4.8 \times 3.1(\mathrm{G})(* 1)\end{array}$ & $\begin{array}{l}\text { FL isolate - Vavraia culicis } \\
\text { floridensis }\end{array}$ \\
\hline
\end{tabular}

(*1) and bold characters - our measurement; (*2) - "macrospores"; (*3) - "microspores"; (*4) - from Culex pipiens; (*5) - from Culiseta longiareolata; $(* 6)$ - from Aedes; $(* 7)$ - from Orthopodomyia; $\left.{ }^{*}\right)$ used in ultrastructural (Canning and Hazard 1982) and mosquito control (Kelly et al. 1981) studies.

Fine structure. Pieces of freshly dissected infected tissues of $S$. littoralis were fixed in $2.5 \%$ glutaraldehyde in cacodylate buffer $(0.1 \mathrm{M}, \mathrm{pH} 7.4)$ at $4^{\circ} \mathrm{C}$ and post-fixed in $1 \%$ osmium tetroxide in the same buffer. Tissue samples were then washed in cacodylate buffer, dehydrated in a graded ethanol series and embedded in Polybed 812 epoxy resin. Ultrathin sections were stained with uranyl acetate and lead citrate and examined with a JEOL 1010 electron microscope equipped with a Megaview $3 \mathrm{CD}$ camera. Some $S$. littoralis tissue samples were fixed for $1 \mathrm{~h}$ in $0.1 \mathrm{M}$ phosphate buffer containing $1 \%(\mathrm{v} / \mathrm{v})$ glutaraldehyde and $1 \%(\mathrm{w} / \mathrm{v})$ osmium tetroxide (Hirsch and Fedorko 1968).

\section{RESULTS}

\section{Light microscopy of the Florida isolate}

Spore size and shape. Spores of the FL isolate Vavraia had the same shape and the nearly the same size, irrespective of the host in which they are propagated. The spores were ovoid, slightly bent and more pointed at the apical pole and had a large vacuole at the posterior pole (Figs. 1, 2, 5). They measured $(\mathrm{n}=50$, fresh) $4.7 \times 2.7(3.9-5.9 \times 2.2-3.3) \mu \mathrm{m}$ when grown in $H . z e a$ or in S. littoralis and $4.9 \times 2.7(3.8-6.4 \times 2.3-3.0) \mu \mathrm{m}$ when grown in $A$. quadrimaculatus larvae. Giemsastained spores of the FL isolate grown in S. littoralis measured $(\mathrm{n}=32) 4.8 \times 3.1(3.4-6.0 \times 2.5-3.6) \mu \mathrm{m}$ (Table. 1).

Life cycle stages. In S. littoralis, the FL isolate of Vavraia infected all larval tissues. The data presented here were obtained from infected muscles. Fresh squashed tissues showed the presence of numerous globular formations with several nuclei representing various sporogonial stages including mature sporophorous vesicles (SPOV) with 16 (mostly) or more spores inside as well as individual spores (Figs. 1, 2, 5-9). Young sporogonial multinucleate stages were of any size between 6 and $25 \mu \mathrm{m}$ (Fig. 6). Mature SPOV with 16 spores were typically slightly oval, about $22-25 \times$ $15-17 \mu \mathrm{m}$ in size, SPOV with higher number of spores were even larger (Figs. 1, 9). There was no indication that advanced sporogonial stages at the onset of SPOV formation were able to divide. Individual spores were elongate ovoid, slightly bent and the posterior vacuole occupied a large portion of the posterior part of the spore (Figs. 2, 5). In young spores stained with Giemsa a body of deep purple colour was situated at the site of the future posterior vacuole (Fig. 3). Mature spores stained with the same stain after hydrolysis in $1 \mathrm{~N} \mathrm{HCl}$ revealed one small, compact nucleus in each spore (Fig. 4). Sporogony evidently proceeded by progressive 


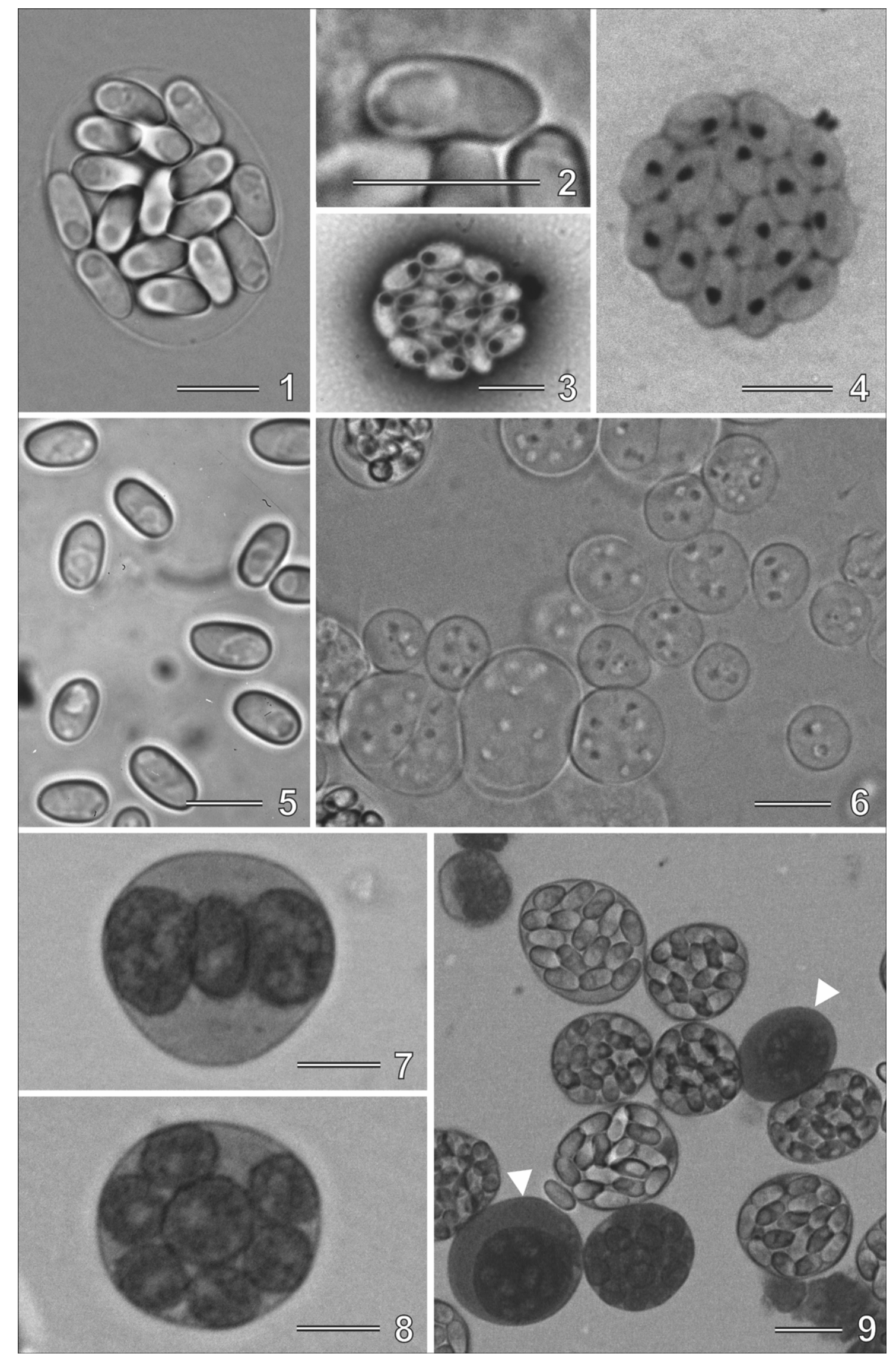




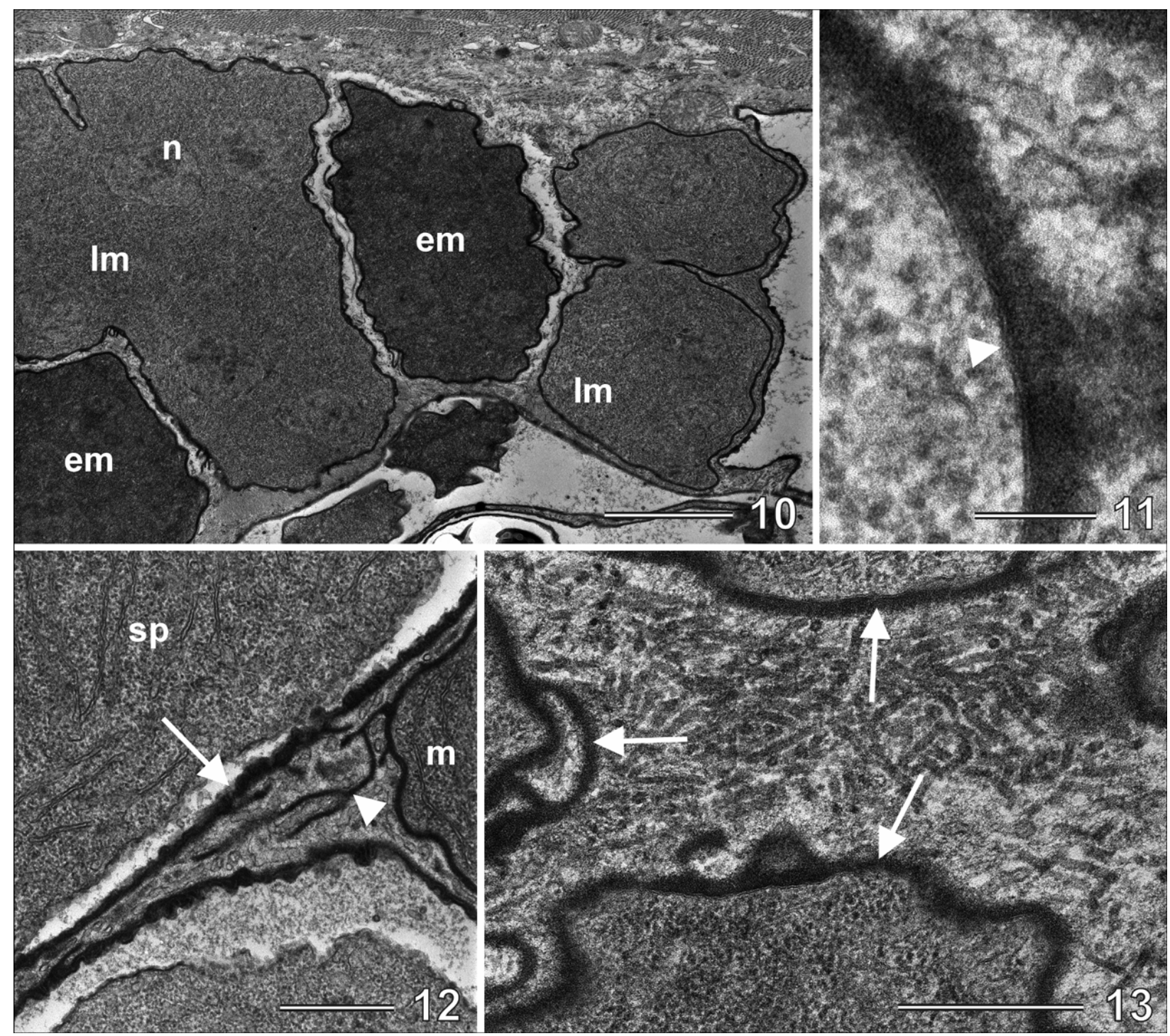

Figs. 10-13. Transmission electron micrographs of merogonial stages of Vavraia culicis floridensis. Fig. 10. Early meronts (em) have an extremely dense cytoplasm as compared with late meronts $(\mathrm{lm})$. The cytoplasm contains a high number of free ribosomes and is so dense that nuclei (n) and the sparse endoplasmic reticulum remain obscured. Fig. 11. High magnification view of the meront border. The plasmalemma (arrowhead) is covered with a $30 \mathrm{~nm}$ thick, electron-dense coat. Fig. 12. Meront (m), showing filiform extensions (arrowhead) of its coat into the host material present among various developmental stages of the parasite (sp, sporont enveloped by the sporophorous vesicle wall, arrow). Fig. 13. Fine tubular structures occur between meront cells (arrows) and seem to represent extensions of the coat material. Scale bars: Fig. $10=2 \mu \mathrm{m}$; Fig. $11=100 \mathrm{~nm}$; Figs. $12,13=500 \mathrm{~nm}$.

Figs. 1-9. Light microscope features of Vavraia culicis floridensis grown in Spodoptera littoralis. Fig. 1. Typical form of sporophorous vesicle with 16 spores. Note the uniformity of spores in size and shape. Fig. 2. Typical spore shape is long ovoid, slightly bent, with a large posterior vacuole occupying the posterior half of the spore. Fig. 3. Sporophorous vesicle with immature spores, Giemsa staining. The posterior vacuole area is intensely stained a deep purple colour at this stage of spore maturation. Fig. 4. Sporophorous vesicle with mature spores. Nuclei are stained by Giemsa stain preceded by acidic hydrolysis. Fig. 5. Fresh spores on an agar monolayer. Fig. 6. Multinucleate sporogonial stages seen in a fresh squash of infected tissue. Note the large size difference of individual sporonts, reflecting that the thick coat is growing as the volume of the cell increases and that the multinucleate sporonts do not divide. Figs. 7, 8. Progressive segmentation of the sporont cell inside the future sporophorous vesicle. Fig. 9. Sporonts (arrowheads) and mature and immature sporophorous vesicles. Scale bars: Figs. 1-5, 7, $8=5 \mu \mathrm{m}$; Figs. $6,9=10 \mu \mathrm{m}$. 
fragmentation of the sporont cell inside the SPOV, as demonstrated by the occurrence of SPOVs that contained a variable number of sporont daughter cells (Figs. $7,8)$.

\section{Light microscopy of the comparative isolates}

Only spores were found on slides used for comparison with the Florida isolate. Their shape was similar to the Florida isolate (Figs. 20-23). The size of spores of the respective isolates is given in Table 1 and is considered in Discussion.

\section{Electron microscopy of the Florida isolate}

Both fixation methods used preserved the fine structure of our material satisfactorily, however, the HirschFedorko fixative-preserved tissues had a more lucent appearance and the membranes of the microsporidia were more conspicuous. The following developmental stages were found in ultrathin sections of $S$. littoralis larvae infected with the FL isolate: meronts, sporonts of various stages of maturation, sporoblasts and spores.

Meronts (Figs. 10-13) were large multinucleate cells, up to $10 \mu \mathrm{m}$ in diameter, with a dense cytoplasm filled with ribosomes which obscured the nuclei. Endoplasmic reticulum (ER) lamellae and Golgi bodies were not well developed in meronts. Meronts were limited by a plasma membrane with an external dense coat approximately 35-40 nm thick (Figs. 10-13). The coat material seemed to have no structure but examination at high magnification suggested that it had a serrated substructure consisting of tightly arranged dense extensions perpendicular to the plasma membrane and embedded in a material of lower electron density. The coat surrounded the meront as a single layer (Fig. 11), however, it sometimes formed long $(1.5 \mu \mathrm{m}$, but probably even longer) filiform extensions into the cytoplasm of infected host cells (Fig. 12). Occasionally these extensions connected daughter meronts after division or formed loops (Fig. 13). Frequently it was possible to find a mat of short tubules in areas between individual meront cells (Fig. 13). These tubules were about $25 \mathrm{~nm}$ thick, but their length could not be estimated accurately due to their twisted nature. The tubules seemed to originate from the dense coat material.

Early sporonts were multinucleate cells similar to meronts but with a less dense cytoplasm (Fig. 14). It was in these stages that transformation of the cell coat into the future SPOV began and was first indicated by the separation of the coat from the plasmalemma of the sporont cell (Fig. 15). The coat was about $80 \mathrm{~nm}$ thick and its general aspect was less homogenous than in meronts. The coat progressively adopted an undulating appearance and became organized into two layers (Fig. 15). Spindle plaques on the nuclei of sporonts were often associated with a group of double membranebounded vesicles which are believed to represent mitosomes (Fig. 19). Conspicuous membranous whorls were often found scattered in low numbers throughout the cytoplasm of some sporonts, but their presence was more typical for stages of advanced sporogony (Fig. 17 and inset).

Late sporogonial stages are demonstrated in Figs. 16 and 17. Progressive division of sporont cells inside the SPOV by rosette-like division (Fig. 16) or by plasmotomy (Fig. 17) led to the formation of smaller, multinucleate daughter sporont cells and finally to individual uninucleate sporoblasts and spores (Fig. 24). The SPOV's were limited by a $40 \mathrm{~nm}$ thick wall, consisting of a dense outer layer $(20 \mathrm{~nm})$, a lucent gap of $8 \mathrm{~nm}$ and an internal dense layer of $12 \mathrm{~nm}$ (Figs. 15, 18). Regions containing a mass of tubules were often present among individual SPOVs. The tubules apparently originated from the coat, were about 40-80 nm thick. The thicker tubules showed layered structure in cross-section (Fig. 18). In the cytoplasm of the late sporogonial stages, conspicuous membranous whorls were observed which consisted of several (usually 6-7) layers of unit membranes arranged in an irregular and loose circle around a very dense central material (Fig. 17, inset). Traces of these whorls were also present in cells transforming into sporoblasts as well as in mature sporoblasts. The SPOVs contained very few inclusions which were in the form of a loose mat composed of an ill-defined material of low electron density together with very fine, electrondense particles (Fig. 28).

Mature spores were oval and had a very dense cytoplasm. They were enveloped by a thick wall consisting of $40 \mathrm{~nm}$ thick electron-dense exospore and an electrontransparent endospore of $90-100 \mathrm{~nm}$ (Fig. 24). The exospore formed a single homogenous layer with a very thin, dense coat on its outer surface (Figs. 25, 26). The polar filament was attached subapically to the internal surface of the anterior end of the spore and its straight part descended at an angle 50 degrees to the longitudinal axis of the spore (Fig. 24). High magnification of the

Figs. 14-19. Transmission electron micrographs of sporogonial stages of Vavraia culicis floridensis. Fig. 14. Early multinucleate sporont. The cytoplasm of the sporonts is more transparent than in meronts and shows spore organelles $(\mathrm{n}-\mathrm{nuclei}$, er - endoplasmic reticulum, $g$ - Golgi vesicles). The plasmalemma detaches inwards from the cell coat and forms an undulating structure. Fig. 15. In sporont (s) the coat adopts an undulating structure after it detaches from the underlying plasma membrane (arrowhead). After transformation into the sporophorous vesicle (sv) the former coat becomes a two-layer structure. Fig. 16. Rosettelike division of a sporont. Fig. 17. Group of sporont daughter cells formed by segmentation of the sporogonial plasmodium in the interior of the sporophorous vesicle. Note the dark structures inside the cells representing concentric membranous whorls (inset). Fig. 18. Areas filled by tubules occur between adjacent sporophorous vesicles. They seem to originate from the sporophorous vesicle walls and have several layers in cross-section. Fig. 19. Group of polar vesicles (mitosomes, arrow) adjacent to the nucleus. Scale bars: Figs. 14, $17=1 \mu \mathrm{m}$, inset $500 \mathrm{~nm}$; Figs. 15, $18=500 \mathrm{~nm}$; Fig. $16=2 \mu \mathrm{m}$; Fig. $19=200 \mathrm{~nm}$. 

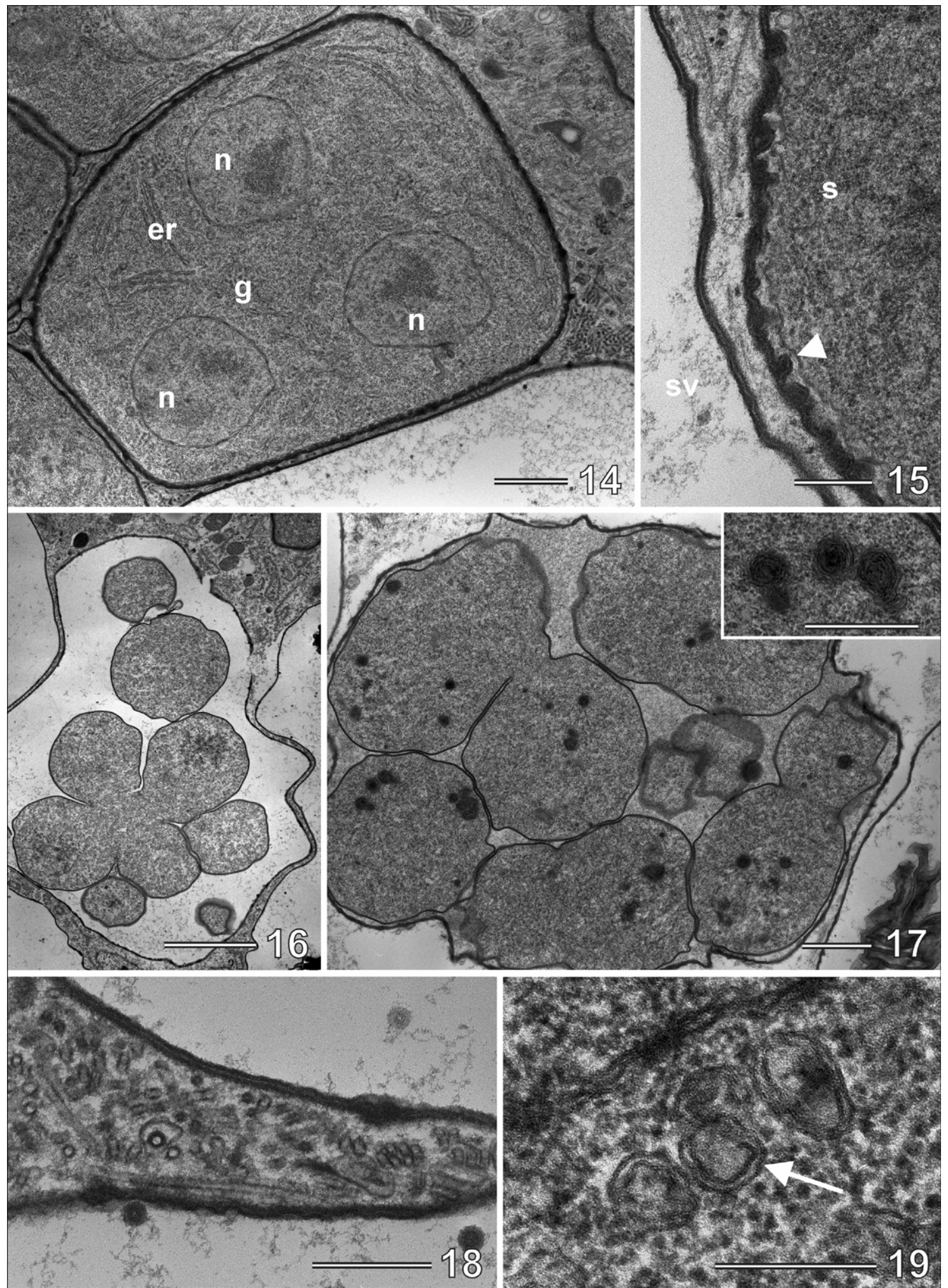
spore apex (Fig. 25) showed that the endospore just above the anchoring disc was replaced by a material of high electron density sandwiched between the anchoring disc and the exospore. This structure is defined here as the "trigger". The polar sac was a mushroom-like structure of high electron density which surrounded (in a cup-like manner) the enormous lamellar polaroplast which filled the anterior third of the spore (Fig. 25). The straight part of the polar filament extended to almost the middle of the spore and then formed a single layer of coils (usually 12). The 8-9 anterior coils measured approximately $130 \mathrm{~nm}$ while the remaining 3-4 coils tapered to approximately $100 \mathrm{~nm}$ in diameter (Fig. 26). The thicker coils had a serrated substructure in crosssection, probably representing sections through fibres (about 22 in number), running obliquely along the length of the filament (Fig. 27). The arrangement of these filaments was clearly revealed in tangential sections of the filament.

\section{DISCUSSION}

\section{Light microscope comparison of the FL and other Vavraia culicis-like isolates}

The spores of the three comparative isolates which we measured and recorded by photography (isolates $\mathrm{CP}$, IT1, AG1) were ovoid in Giemsa smears and their shape was similar to the FL isolate. Spore size of the respective isolates is listed in Table 1 and can be compared in Figs. 20-23. Analysis of morphometric data indicated significant difference in spore length of the respective isolates. Two spore size groups were revealed: the isolates CP and IT1, both of them representing parasites found in Culex pipiens, had smaller spores. Their spores were of the same length with highly significant statistical support $(p<0.001)$. The spores of the remaining two isolates (FL and AG1) had spores of the same length $(\mathrm{p}<0.001)$, but their spores were significantly larger when compared with the isolates CP and IT1. As far as the Vavraia-like parasite found in Anopheles stephensi is concerned (isolate AS in Table 1), only published data can be discussed because no Giemsa-stained slides of this isolate exist (Lobo, pers. comm.). This isolate seems also to have bigger spores than the isolates $\mathrm{CP}$ and IT1. Differences in spore width of the examined isolates had no statistical significance. Morphometric data clearly indicate that the Florida, AG1 and possibly also the AS isolate, are different from the type material of Vavraia culicis Weiser. Implication of this finding on taxonomy is discussed at the end of the paper.

Only published data could be used for comparison of the size and shape of sporophorous vesicles (SPOV) in individual isolates as no well preserved spore groups were found in Giemsa-stained slides of the respective isolates CP, IT1 and AG1 used for the comparison with the FL isolate. The FL isolate forms typically 16 spores per SPOV, rarely 32 or more. Weiser (1946) reported that SPOVs of the CP isolate contained 10-60 spores.
Canning (1957) reported 8 to 100 or more spores per SPOV in the AG1 isolate, while Weiser and Coluzzi (1972) indicated that there were 30-60 spores per SPOV in the IT parasites. Canning and Hazard (1982) and Diarra and Toguebaye (1991) stated that there are 8, 16, 32 or more spores per SPOV (respective isolates IT2 and AG2). Also the size of SPOVs varies in reports by different authors. Canning (1957) stated that the "cysts" were spherical or elongate ovoid and measured $10.3 \times$ 8.8 to $19 \times 19 \mu \mathrm{m}$ when fresh $(10.3-26.5 \times 11.8-17.6$ $\mu \mathrm{m}$, fixed) (isolate AG1). Weiser (1946) reported SPOVs that measured $40-50 \times 30 \mu \mathrm{m}$ (fixed) in the CP isolate. The FL isolate SPOVs are (on average) $22-25 \times$ $15-17 \mu \mathrm{m}$ in size.

\section{Ultrastructure of the Florida isolate}

The fine structure of the FL isolate of Vavraia is generally similar to that of the other two respective isolates used in ultrastructural studies (Canning and Hazard 1982, Diarra and Toguebaye 1991). It should be mentioned here that the isolate used by Canning and Hazard (1982) was most probably identical to the IT isolates (Table 1). It originated from infected Culiseta longiareolata found in the same basin as the original IT isolates (Canning, pers. comm.). The coat structure of meronts as described in detail by Canning and Hazard (1982) is similar to the observations presented here. Of special interest is their observation that the seemingly homogenous coat has a substructure (see fig. 15 in Canning and Hazard 1982) which was confirmed in this study. Although very difficult to resolve, it appears that the coat is represented by a mat of very small vesicles protruding out of the electron-dense deposits on the outer surface of the plasma membrane. These vesicles are embedded in an electron-dense matrix. In meronts the coat forms sometimes branching extensions several micrometres in length (Fig. 12). These extensions were believed to be strands of the coat material that persisted as connections between segments of dividing meront (Canning and Hazard 1982). They are similar to filiform extensions between dividing meronts in Trachipleistophora hominis (Hollister et al. 1996). Physiological significance of such extensions is not known, but probably they mediate host-parasite transport of nutrients. High magnification micrographs suggest that some other membranous material projects from the coat into the regions surrounding meronts and early sporonts in the form of fine tubular material (Fig. 13). This tubular material was not reported in previous investigations on the fine structure of $V$. culicis. Very similar tubular formations occur in Trachipleistophora hominis, a microsporidian phylogenetically close to $V$. culicis ("tubulofilaments" of Weidner et al. 1997, 1999). Similar fibro-tubular formations were seen also in Trachipleistophora anthropophthera (Vávra et al. 1998).

Sporogony proceeded by sequential division of the multinucleate sporont into smaller parts, first with several nuclei each (plasmotomy) and later with individual 

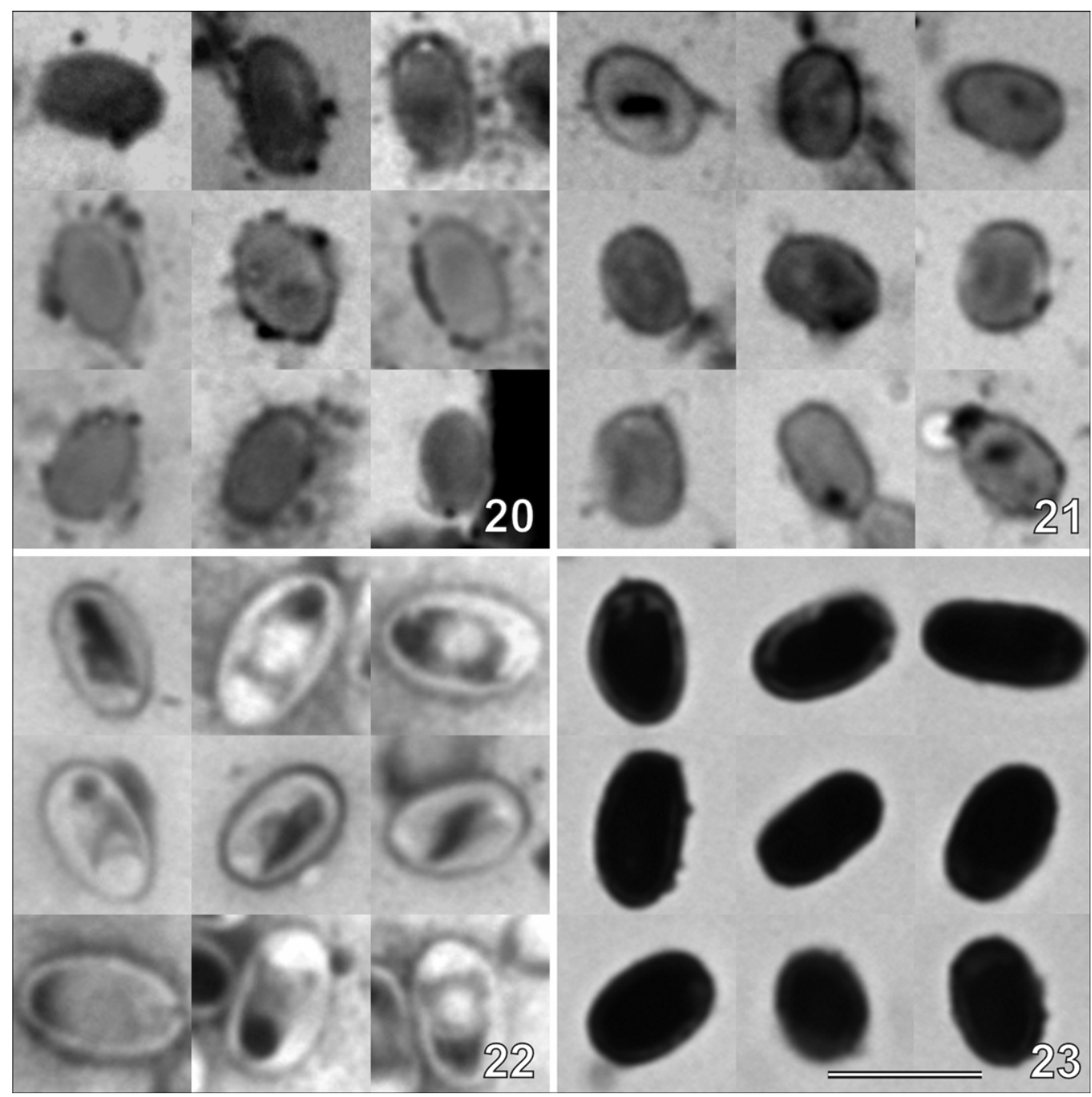

Figs. 20-23. Giemsa-stained spores of four isolates of Vavraia culicis-like microsporidia. Fig. 20. The CP isolate - type isolate for Vavraia culicis (Weiser). Fig. 21. The IT1 isolate. Fig. 22. The FL isolate (= Vavraia culicis floridensis). Fig. 23. The AG1 isolate. Scale bar $=5 \mu \mathrm{m}$. (Figs. 20-23 are at the same magnification.)

uninucleate cells. This division involves only the plasma membrane of the sporont and its daughter cells while the SPOV is not involved although its volume increased during the process. We observed, although rarely, the division of the sporont via a rosette stage as described by Canning and Hazard (1982). Sporogony began with the detachment of the sporont plasma membrane from the overlying coat which transforms into the SPOV. This change is marked by the separation of the seemingly homogenous coat into two layers. First the SPOV had an undulating appearance but later, when sporoblasts and spores were formed, the wall is nearly smooth and it is possible that the increase of the SPOV surface area is partly due to the stretching of the coat material. The increase in volume and surface area of the SPOV is evidently a rapid event as we never saw the SPOV dividing. The increase of the SPOV volume and surfacearea between early sporogony and its final size when spores were formed was more than 70 fold in volume and about 17 times in surface area. Of interest here is the fact that the cell coat of $V$. culicis evidently represents a mechanically resistant envelope since even the early stages in sporogony were resistant to postmortem osmotic changes (see Fig. 6).

Unexplained remains the occurrence of the membrane whorls observed in sporonts. These structures do not appear to be homologous to the paramural bodies described in some microsporidia as club-shaped whorls originating from the plasmalemma (Vávra 1976). Three, mutually exclusive possibilities, are to be considered. The whorls may represent an aberrant form of the double-membrane vesicles which are most probably mitosomes (Vávra 2005). Their location close to the nucleus in some cases seems to suggest this possibility. Polar filament or polaroplast primordia are additional possibilities and finally, they could represent a membrane pool that is required for the rapid sporont divisions observed. 


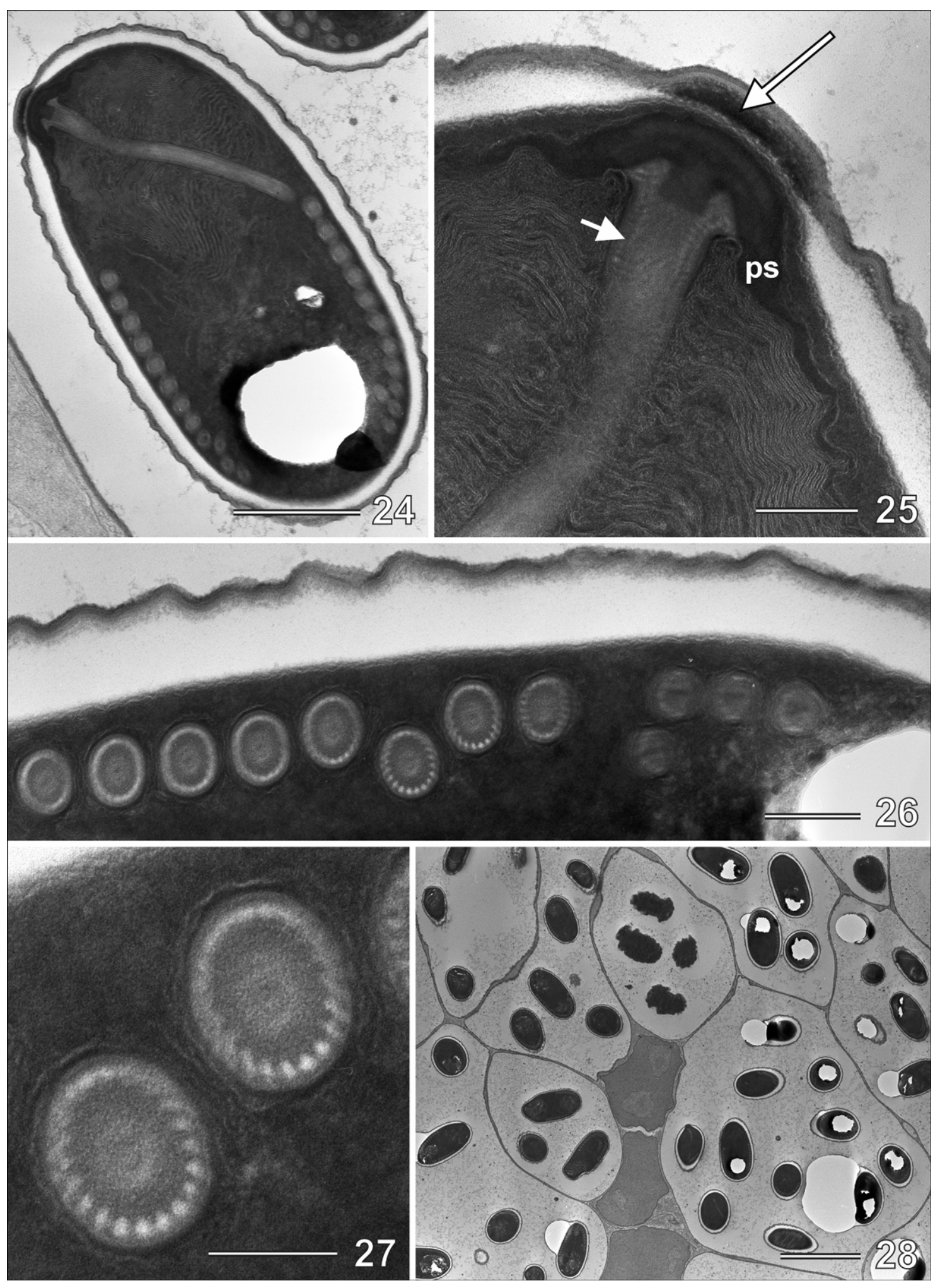


The spores of the Florida isolate have a markedly subapical location of the anchoring disc. This is similar to what has been reported for the isolate studied by Diarra and Toguebaye (1991) as well as for the two described species of Trachipleistophora (Vávra et al. 1998). Also, the polar filament is of similar length as well as the ratio of thick/thin coils for these two isolates. In contrast, Canning and Hazard (1982) reported 15 turns of the filament and although the anisofilar character of the filament was not mentioned, the published image shows 11 thicker and 4 thinner coils. Fukuda et al. (1997) observed 11 isofilar coils of the polar filament in the spores of Vavraia from Ae. albopictus, i.e. in the same isolate described here. We believe that they actually saw such polar filament structure in not fully mature spores, which have a lower number of filamentcoils. The number of coils, their thick/thin coils ratio and their internal organisation in the Florida isolate is similar to that observed in Vavraia lutzomyiae, a parasite of Lutzomyia longipalpis (Matos et al. 2006). This raises the possibility that $V$. lutzomyiae is actually an isolate of $V$. culicis. As the paper by Matos et al. (2006) contains no molecular data, the eventual identity of $V$. lutzomyiae and $V$. culicis remains unresolved. The presence of the "trigger" (dense, stopper-like structure in the wall just above the anchoring disc) has not been reported for the microsporidia. We believe that it is probable that through this structure the signal for spore activation leading to polar filament discharge is mediated.

\section{Type slide deposition of Vavraia culicis-like microsporidia}

Only two type slides of $\mathrm{V}$. culicis from the original finding of the parasite in Culex pipiens larva exist (Weiser, pers. comm.). They are deposited in the collection of microsporidian slides of J. Weiser in Prague and at the Natural History Museum in Vienna. Other Weiser's slides labeled V. culicis and stored at the Natural History Museum in Vienna, Austria record the parasite found by Weiser and Coluzzi $(1964,1972)$ in Culex pipiens and Culiseta longiareolata in Monticello, Italy. The Florida isolate slides are deposited in the International Protozoan Type Slide Collection, Department of Invertebrate Zoology, National Museum of Natural History, Smithsonian Institution, Washington, D.C., USA, Acc. Nos. USNM 1102485 and USNM 1102486. Slides are also held in the collection of J. Becnel,
Gainesville, FL. No other slide depositions exist as far as we know.

\section{Molecular biology of the Florida isolate}

This isolate is the one of the two V. culicis-like microsporidia for which molecular data exist. The 16SrDNA sequence of 1,364 nucleotides in length was established by Cheney et al. (2000) (GenBank Acc. No. AJ252961) and was used for the phylogenetic analysis of the Pleistophora-like microsporidia. Phylogenetic analysis of the Florida isolate of Vavraia was further studied by Cheney et al. (2001) using nucleotide sequences of the A-G region of the largest subunit of RNA polymerase II (RPB1) (GenBank Acc. No. AJ278956). Both of these studies supported a close phylogenetic relationship between the Florida isolate of Vavraia and Trachipleistophora hominis isolated from man (evaluated by Lobo et al. 2006 to represent $97 \%$ identity). Recently Vávra et al. (2006) found that in the RPB1 gene of the Florida isolate, a specific 16 nucleotide sequence is missing. The absence of this sequence effectively distinguishes the genera Vavraia and Trachipleistophora. Most recently, a part of the 16S-rDNA sequence of the Florida isolate was compared with the sequence of the same gene in a Vavraia culicis-like microsporidian found in a laboratory colony of Anopheles stephensi in Portugal (AS isolate). Both sequences are $99 \%$ identical (23 nucleotides different in an amplicon of 726 nucleotides) (Lobo et al. 2006).

\section{ENVOI. The identity of the Florida isolate}

The investigated FL isolate undoubtedly fulfils the generic characters of the genus Vavraia as defined by Weiser (1977) and later expanded to include ultrastructural characters (Canning and Hazard 1982, Diarra and Toguebaye 1991). As shown above, according to all previous authors working with the FL isolate, this isolate has been considered to represent $V$. culicis (Weiser, 1947). However, as shown here, the FL isolate is not identical with $V$. culicis (Weiser, 1947). In fact the significantly different spore size when the type $V$. culicis is compared with the FL isolate indicates that these two organisms are different. As reported above, the morphometric comparison of several isolates shows that this difference concerns not only the FL isolate but also the AG1 isolate. This seems to suggest that the believed single species $V$. culicis is in reality a group of related microsporidia. However, to define relationships of more recent isolates to the original type material of $V$. culicis

Figs. 24-28. Transmission electron micrographs of spores and sporophorous vesicles of Vavraia culicis floridensis from larvae of Spodoptera littoralis. Fig. 24. Longitudinal section through the middle of a spore shows the subapically located anchoring disc, the straight part of the polar filament, and its 8 thicker and 4 thinner coils. The spore wall consists of a thick transparent endospore and a thin electron-dense exospore. Fig. 25. Fine structure of the spore apex. Note the presence of a very dense material between the exospore and the anchoring disc (the trigger, long arrow). Polar sac (ps) tops the lamellar polaroplast. Short arrow marks the site where electron-lucent fibres, forming the inner tube of the polar filament (see Figs. 26, 27), are visible. Note that the exospore bears a thin layer of dense material on its outer face. Fig. 26. Typical arrangement of the coils of the polar filament showing 8 thicker and 4 thinner coils. Fig. 27. The thicker coils show about 22 dot-like structures forming a ring inside the crosssectioned polar filament. Fig. 28. Sporophorous vesicles containing sporoblasts transforming into spores and nearly mature spores. Note that except for spores, the sporophorous vesicles are nearly devoid of any internal material. Scale bars: Fig. $24=500$ nm; Figs. $25,26=200$ nm; Fig. $27=100 \mathrm{~nm}$; Fig. $28=5 \mu \mathrm{m}$. 
on a set of characters, more precise than spore size, is presently impossible. The number of spores on the existing two type slides of $V$. culicis is too small to allow the application of molecular biology methods and the eventual attempt to use these slides for such purpose is at risk to destroy of the type material. Evidently, without rediscovery of a Vavraia-like microsporidium from the original host and original geographic area, the question of the identity of the FL and other isolates remains a matter of conjecture. However, there is one factor speaking in favour of the idea that the FL isolate is a different organism than the original $V$. culicis. The FL isolate was isolated from a different host and from a vastly different geographic area. To presume absolute identity of two organisms isolated from different hosts and different continents does not correspond with the present understanding of biological diversity and evolution. As we believe that the FL isolate is not identical with $V$. culicis (Weiser, 1947), the question remains, however, how taxonomically treat the FL isolate. Under the lack of comparative data which would allow us to designate the FL isolate as a new species, it seems best to treat the FL isolate (and consequently also the original CP type isolate) as subspecies of $V$. culicis. In such way the relationship to the original $V$. culicis is expressed and the organism is firmly integrated in microsporidia classification. It is most probable that future research will show that microsporidia recognized as Vavraia culicis-like are actually a group of closely related mosquito microsporidia of low host specificity and more or less adapted to individual hosts. The small, yet significant difference in the 16S rRNA gene sequence of the Vavraia culicis-like microsporidium (isolate AS) vis-à-vis the FL isolate ( $99 \%$ identity) (Lobo et al. 2006) seems to support such a possibility.

\section{Taxonomic definition of the respective $V$. culicis type $C P$ and the $V$. culicis-like FL isolates}

The CP isolate:

Vavraia culicis culicis (Weiser, 1947) Weiser, 1977

Type host: Culex pipiens Linnaeus, 1758.

Type locality: Pond Koželužský, Chotěboř (4943'0'N, 1540’0’E), Czech Republic, Europe, 1943.

Merogony: Not described.

Sporogony: Uninucleate sporont 4-4.5 $\mu \mathrm{m}$, divides 5 times and produces plasmodia with 32 nuclei and sporophorous vesicles with 32 spores.

Spores: Ovoid, $4.0 \times 2.5 \mu \mathrm{m}$ (fresh), $3.7 \times 2.34 \mu \mathrm{m}$ (fixed).

Molecular biology characters: Unknown.
Deposition of type: Two slides labeled "Plistophora culicis, Culex pipiens, Chotěboř, 1943" in slide collection of Dr. J. Weiser, Prague, Czech Republic and at the Natural History Museum, Vienna, Austria.

The FL isolate:

\section{Vavraia culicis floridensis subsp. n.}

Differential diagnosis: Differs from $V$. culicis culicis by larger spores.

Type host: Aedes albopictus (Scuse, 1845).

Type locality: Archer, Florida, Alachua County (2928'34.83”N, 82³6’20.55”W), 1991.

Merogony: Meronts have a 30-40 nm thick electrondense coat, forming occasionally long electron-dense filiform extensions and $25 \mathrm{~nm}$ thick tubular formations, protruding into the cytoplasm of the host cell.

Sporogony: Sporonts divide by rosette-like division or plasmotomy. Their coat forms transient $40-80 \mathrm{~nm}$ thick tubules. Mature sporophorous vesicles have a 40 $\mathrm{nm}$ thick wall, consisting of three layers.

Spores: Ovoid, slightly bent, 4.7-4.9 $\times 2.7 \mu \mathrm{m}$ (fresh), $4.8 \times 3.1$ (Giemsa-stained), with a $40 \mathrm{~nm}$ thick exospore and a 90-100 nm thick endospore. Polar filament has $50^{\circ}$ tilt. An electron-dense layer is sandwiched between the anchoring disc and the exospore. Polar filament anisofilar, with usually 12 coils (8-9 anterior coils $130 \mathrm{~nm}$ thick and displaying in cross-section about 22 fibre-like structures), and 3-4 posterior coils of 100 nm.

Other hosts: Transmissible experimentally to Anopheles quadrimaculatus, Aedes aegypti, Helicoverpa zea and Spodoptera littoralis.

Molecular biology characters: 16S-rDNA sequence GenBank Acc. No. AJ252961, RPB1 gene sequence GenBank Acc. No. AJ278956). In the RPB1 gene there is not the 16-bp-long insertion motive (GTGAAGTAACATTAA) between nucleotides 562 and 563.

Deposition of type: International Protozoan Type Slide Collection, Department of Invertebrate Zoology, National Museum of Natural History, Smithsonian Institution, Washington, D.C., USA, Acc. Nos. USNM 1102 485 and USNM 1102486.

Acknowledgments. This work was supported by the Research Project of the Institute of Parasitology, ASCR, No. Z60220518 and by the Research Grant No. 524/07/1003 of the Grant Agency of the Czech Republic. We extend our thanks to Mrs. Eva Kirchmannová for expert help in electron microscopy and Genie White and Heather Furlong (USDA/ARS) for technical help in maintaining the infected insect colonies. Prof. E.U. Canning and Dr. J. Weiser are thanked for providing slides for comparison.

\section{REFERENCES}

Agnew P., Bedhomme S., Haussy C., Michalakis Y. 1999: Age and size at maturity of the mosquito Culex pipiens infected by the microsporidian Vavraia culicis. Proc. R. Soc. Lond. B 266: 947-952.

ANDREADIS T.G. 2007: Microsporidian parasites of mosquitoes. In: T.G. Flore (Ed.), Biorational Control of Mosquitoes. Bull. No. 7, Am. Mosq. Control Assoc., 23, pp. 3-29.
BECNEL J.J., White S.E., ShAPIRO A.M. 2005: Review of microsporidia-mosquito relationships: from the simple to the complex. Folia Parasitol. 52: 41-50.

Bedhomme S., Agnew P., Vital Y., Sidobre C., Michalakis Y. 2005: Prevalence-dependent costs of parasite virulence. PLoS Biol. Aug. 3(8): e262. 
Biron D.G., Agnew P., Marche L., Renault L., Sidobre C. Michalakis Y. 2005: Proteome of Aedes aegypti larvae in response to infection by the intracellular parasite Vavraia $\mathrm{Cu}$ licis. Int. J. Parasitol. 35: 1385-1397.

CANNING E.U. 1957: On the occurence of "Plistophora culicis" Weiser in Anopheles gambiae. Riv. Malariol. 36: 1-3.

CANNING E.U., HAZARD E.I. 1982: Genus Pleistophora Gurley, 1983: an assemblage of at least three genera. J. Protozool. 29: 39-49.

CHAPMAN H.C. 1974: Biological control of mosquito larvae. Ann. Rev. Entomol. 19: 33-59.

CHENEY S.A., LAFRANCHI-TRISTEM N.J., BOURGES D., CANNING E.U. 2001: Relationship of microsporidian genera with emphasis on the polysporous genera, revealed by sequences of the largest subunit of RNA polymerase II (RPB1). J. Eukaryot. Microbiol. 48: 111-117.

CHENEY S.A., LAFRANCHI-TRISTEM N.J., CANNING E.U. 2000: Phylogenetic relationship of Pleistophora-like microsporidia based on small subunit ribosomal DNA sequences and implications for the source of Trachipleistophora hominis infections. J. Eukaryot. Microbiol. 47: 280-287.

Clark T.B., FuKUdA T. 1971: Pleistophora chapmani n. sp. (Cnidospora: Microsporidia) in Culex territans (Diptera: $\mathrm{Cu}-$ licidae) from Louisiana. J. Invertebr. Pathol. 18: 400-404.

DiARRA K., TOGUEBAYE B.S. 1991: On the development cycle and ultrastructure of Vavraia culicis Weiser, 1947 (Microsporida, Pleistophoridae) with comments on the taxonomy of the genus Vavraia Weiser, 1977. Eur. J. Protistol. 27: 134 140.

FUKUDA T., WILLIS O.R., BARNARD D.R. 1997: Parasites of the Asian Tiger Mosquito and other container-inhabiting mosquitoes (Diptera: Culicidae) in Northcentral Florida. J. Med. Entomol. 34: 226-233.

HAZARD E.I., CHAPMAN H.C. 1977: Microsporidian pathogens of Culicidae (mosquitoes). In: D.W. Roberts and M.A. Strand (Eds.). Bull. WHO Vol. 55 (Suppl.), pp. 63-107.

HIRSCH J.G., FEDORKO M.E. 1968: Ultrastructure of human leucocytes after simultaneous fixation with glutaraldehyde and osmium tetroxide and "postfixation" in uranyl acetate. J. Cell Biol. 88: 615-627.

Hollister W.S., CANNing E.U., Weidner E., Field A.S., KENCH J., MARRIOTT D.J. 1996: Development and ultrastructure of Trachipleistophora hominis n. g., n. sp. after in vitro isolation from an AIDS patient and inoculation into athymic mice. Parasitology 112: 143-154.

Kelly J.F., ANTHONY D.W., DillaRd C.R. 1981: A laboratory evaluation of the microsporidian Vavraia culicis as an agent for mosquito control. J. Invertebr. Pathol. 37: 117-122.

LARSSON R. 1986: Ultrastructure study and description of Vavraia holocentropi $\mathrm{n}$. sp. (Microspora: Pleistophoridae), a parasite of larvae of the caddisfly Holocentropus dubius (Trichoptera, Polycentropididae). Protistologica 22: 441-452.

Lobo M.L., Silveira H., Ramos S., XiaO L., Matos O. 2006 Characterization of a pathogen related to Vavraia culicis detected in a laboratory colony of Anopheles stephensi. J. Eukaryot. Microbiol. 53 (S1): S65-S67.

Matos E., MendoncA I., AZEVEDo C. 2006: Vavraia lutzomyiae n. sp. (Phylum Microspora) infecting the sandfly Lutzomyia longipalpis (Psychodidae, Phlebotominae), a vector of human visceral leishmaniasis. Eur. J. Protistol. 42: 21-28.
REYNOLDS D.G. 1966: Infection of Culex fatigans with a microsporidian. Nature 210: 967.

REYNOLDS D.G. 1970: Laboratory studies of the microsporidian Plistophora culicis (Weiser) infecting Culex pipiens fatigans Wied. Bull. Entomol. Res. 6: 339-349.

REYNOLDS D.G. 1971: Parasitism of Culex fatigans by Nosema stegomyiae. J. Invertebr. Pathol. 18: 429.

REYNOLDS D.G. 1972: Experimental introduction of a microsporidian into a wild population of Culex pipiens fatigans Wied. Bull. WHO 46: 807-812.

Rivero A., Agnew P., Bedhomme S., Sidobre C., Michalakis Y. 2007: Resource depletion in Aedes aegypti mosquitoes infected by the microsporidia Vavraia culicis. Paarsitology 134: $1355-1362$.

UNDEEN A.H., VÁVRA J. 1997: Research methods for entomopathogenic protozoa. In: L.A. Lacey (Ed.), Biological Techniques. Manual of Techniques in Insect Pathology. Academic Press, San Diego, Boston, New York, Sydney, Tokyo, Toronto, pp. 117-151.

VÁVRA J. 1976: The occurrence of paramural bodies in microsporidia. J. Protozool. 23: 21A.

VÁVRA J. 2005: "Polar vesicles" of microsporidia are mitochondrial remnants ("mitosomes")? Folia Parasitol. 52: 193-195.

VÁvra J., HorÁK A., MOdRÝ D., LuKEŠ J., KOUdElA B. 2006: Trachipleistophora extenrec n. sp. a new microsporidian (Fungi: Microsporidia) infecting mammals. J. Eukaryot. Microbiol. 53: 464-476.

VÁVRA J., MADDOX J.V. 1976: Methods in microsporidiology. In: I.A. Bulla and T.C. Cheng (Eds.), Comparative Pathobiology. Vol.1. Plenum Press, New York, London, pp. 281-319.

VÁVRA J., YACHNIS A.T., SHADDUCK J.A., ORENSTEIN J.M. 1998: Microsporidia of the genus Trachipleistophora causative agents of human microsporidiosis: description of Trachipleistophora anthropophthera n. sp. (Protozoa: Microsporidia). J. Eukaryot. Microbiol. 45: 273-283.

Weidner E.H., CANNING E.U., Hollister W.S. 1997: The plaque matrix (PQM) and tubules at the surface of intramuscular parasite Trachipleistophora hominis. J. Eukaryot. Microbiol. 44: 359-365.

Weidner E.H., Canning E.U., Rutledge C.R., Meek C.L. 1999: Mosquito (Diptera: Culicidae) host compatibility and vector competence for the human myositic parasite Trachipleistophora hominis (Phylum Microspora). J. Med. Entomol. 36: 522-525.

WEISER J. 1946: [A study of microsporidia from Czech aquatic insect larvae]. Věstn. Čs. Spol. Zool. 10: 245-272. (In Czech.)

WEISER J. 1947: [A key for the determination of microsporidia]. Práce Mor. Př́r. Spol. 18: 1-64. (In Czech.)

WEISER J. 1977: Contribution to the classification of microsporidia. Věstn. Čs. Spol. Zool. 41: 308-320.

WeISER J. 1978: Production of the microsporidian Plistophora culicis in substitute host. Folia Parasitol. 25: 365.

WeISER J., COLUZZI M. 1964: Plistophora culisetae n. sp., a new microsporidian (Protozoa Cnidosporidia) in the mosquito $\mathrm{Cu}$ liseta longiareolata (Maquart 1838). Riv. Malariol. 43: 5155 .

Weiser J., ColuzZi M. 1972: The microsporidian Plistophora culicis Weiser, 1946 in different mosquito hosts. Folia Parasitol. 19: 197-202

Accepted 4 June 2007 